\title{
Resource recovery from waste streams in a Water- Energy-Food nexus perspective: toward more sustainable food processing
}

A. Udugama, Isuru; Petersen, Leander A. H. ; Falco, Francesco C.; Junicke, Helena; Mitic, Aleksandar; Flores Alsina, Xavier; Mansouri, Seyed Soheil; Gernaey, Krist V.

Published in:

Food and Bioproducts Processing

Link to article, DOI:

10.1016/j.fbp.2019.10.014

Publication date:

2020

Document Version

Peer reviewed version

Link back to DTU Orbit

Citation (APA):

A. Udugama, I., Petersen, L. A. H., Falco, F. C., Junicke, H., Mitic, A., Flores Alsina, X., Mansouri, S. S., \& Gernaey, K. V. (2020). Resource recovery from waste streams in a Water- Energy-Food nexus perspective: toward more sustainable food processing. Food and Bioproducts Processing, 119, 133-147. https://doi.org/10.1016/j.fbp.2019.10.014

\section{General rights}

Copyright and moral rights for the publications made accessible in the public portal are retained by the authors and/or other copyright owners and it is a condition of accessing publications that users recognise and abide by the legal requirements associated with these rights.

- Users may download and print one copy of any publication from the public portal for the purpose of private study or research.

- You may not further distribute the material or use it for any profit-making activity or commercial gain

- You may freely distribute the URL identifying the publication in the public portal 


\section{Journal Pre-proof}

Resource recovery from waste streams in a Water-Energy-Food nexus perspective: toward more sustainable food processing

Isuru A. Udugama, Leander A.H. Petersen, Francesco C. Falco, Helena Junicke, Aleksandar Mitic, Xavier Flores Alsina, Seyed

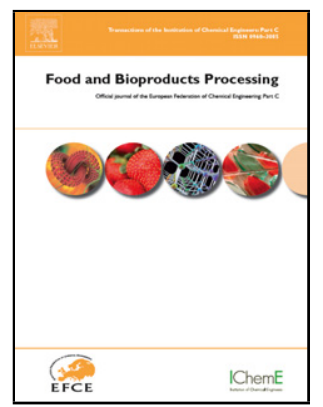
Soheil Mansouri, Krist V. Gernaey
PII:
S0960-3085(19)30025-2
DOI: https://doi.org/10.1016/j.fbp.2019.10.014
Reference:
FBP 1167

To appear in:

Food and Bioproducts Processing

Received Date:

24 April 2019

Revised Date:

13 October 2019

Accepted Date:

23 October 2019

Please cite this article as: Udugama IA, Petersen LAH, Falco FC, Junicke H, Mitic A, Alsina XF, Mansouri SS, Gernaey KV, Resource recovery from waste streams in a Water-Energy-Food nexus perspective: toward more sustainable food processing, Food and Bioproducts Processing (2019), doi: https://doi.org/10.1016/j.fbp.2019.10.014

This is a PDF file of an article that has undergone enhancements after acceptance, such as the addition of a cover page and metadata, and formatting for readability, but it is not yet the definitive version of record. This version will undergo additional copyediting, typesetting and review before it is published in its final form, but we are providing this version to give early visibility of the article. Please note that, during the production process, errors may be discovered which could affect the content, and all legal disclaimers that apply to the journal pertain.

C 2019 Published by Elsevier. 


\title{
Resource recovery from waste streams in a Water- Energy-Food nexus perspective: toward more sustainable food processing
}

Isuru A. Udugama ${ }^{1+}$, Leander A. H. Petersen ${ }^{1,2+}$, Francesco C. Falco ${ }^{1}$, Helena Junicke ${ }^{1}$, Aleksandar Mitic ${ }^{1}$, Xavier Flores Alsina ${ }^{1}$, Seyed Soheil Mansouri ${ }^{1}$, Krist V. Gernaey ${ }^{1 *}$

1. Process and Systems Engineering Center (PROSYS),Department of Chemical and Biochemical Engineering, Technical University of Denmark, Søltofts Plads, Building 229, 2800 Kongens Lyngby, Denmark

2. Unibio A/S, Niels Bohrs Allé 17, 5230 Odense M, Denmark

*Corresponding Author: kvg@kt.dtu.dk

+Authors contributed equally to the manuscript

\section{Highlights}

- Resource recovery (RR) can reduce environmental impact of food processing

- Four case studies highlight different potential RR technologies in this paper

- Understanding industrial needs is essential for successful RR commercialisation

- Risk awareness of industry and raising private equity are key RR challenges

\begin{abstract}
The recovery of resources from waste streams including food production plants can improve the overall sustainability of such processes from both economic and environmental points of view. This is because resource recovery solutions will be instrumental in overcoming the grand societal challenges in relation to the Water-Energy-Food (WEF) nexus in one of many aspects. Identification, development and implementation of resource recovery solutions in an industrial setting is a challenge that requires careful assessment of environmental impacts, technology readiness level (TRL), economics as well as other implementation aspects. This manuscript will first introduce these multi-disciplinary concepts followed by four case studies that are each at a different level of technological maturity and have a unique economic value proposition. The technologies demonstrated in these case studies directly convert either food waste, waste energy or wastewater into valuable raw materials. Using the case study experience as a basis, a
\end{abstract}


roadmap to commercialisation is discussed where the focus is on understanding industrial needs, the role of industrial symbiosis and the current challenges that must be overcome. To this end, the objective of this manuscript is to go beyond the purely single-faceted technical discussion and provide an insight into the multi-faceted aspects of commercialising resource recovery technology development, which would be a key pillar in realising the future circular economy in line with UN's sustainable development goals.

Keywords: Resource Recovery, Circular Economy, Commercialisation, Technology, Environment, Techno-Economics

\section{Introduction}

Recovery of resources from waste streams continues to be an area of active research and commercial interest due to the promise of improving both economic and environmental performances of a process [1-3]. Resource recovery may achieve this feat by creating additional revenue streams through the recovery of valuable resources that would otherwise need to be treated as waste. Therefore, once a resource recovery opportunity is identified, potentially a treatment endeavour may turn into a recovery activity with clear forecasted economic profit. Due to this unique value proposition, resource recovery has been considered a core platform concept in transitioning from a linear economy to a circular economy [4]. In the domain of the food and food ingredients industry, the concept of resource recovery has already been explored, both in terms of separating valuable material from industrial food waste as well as through using the food waste as a substrate/reactant in creating valuable compounds through fermentation or traditional chemical reactions [3,5-7]. A steady increase in the global population and rising global wealth have prompted an increased consumption of animal proteins [8] which puts a severe burden on agricultural production in general. Resource recovery can play a key role in the reduction of resources used in a food production process, which ultimately reduces the overall resources used globally (assuming a similar level of consumption)

A prime example of industrial scale inventory integration (mass and energy) within a production process is traditional petrochemical refining. In petrochemical refining crude oil containing numerous types of hydrocarbon compounds is transformed into a set of target products via integrated separation and reaction operations, while heat generated in exothermic units is distributed to endothermic ones through heat integration [9]. While crude oil refining, by no stretch of the imagination, is a resource recovery example, the operations it implements for resource integration provide inspiration in transitioning from often single product food processing operations into more resource efficient processes. This type of transformation has already influenced the industrial scale food production such as the dairy industry. In the dairy industry, whey protein rich wastewater is produced during the cheese making process, and was traditionally treated and discarded as waste product with no commercial value [10,11]. However, with the development of efficient separation technologies in recent decades, whey proteins in the waste streams are now separated and further 
refined into high value speciality products such as whey protein isolates, resulting in a significant boost to a dairy plants bottom line while also reducing the wastewater treatment burden from cheese production $[10,11]$.

Looking at the whey protein solution in detail illustrates one key aspect to implementing resource recovery technologies, which is the availability and readiness of a given resource recovery technology to be implemented in an industrial setting. Technology readiness is one way of putting this level of development into perspective, through the technology readiness level (TRL) metric, which was originally developed by NASA to rate how close to implementation (market) a given technology is [12]. The TRL metric runs from 1-9, with a TRL 1 given to a concept/idea which has been proven in a lab environment to a TRL 9 given to a technology that has been proven in real world operations [12]. Since its inception, the TRL concept has been adopted by other sectors and organisations to better understand the current state of a project or technology development [13]. In the case of whey protein it can be seen that despite knowing the value of recovered whey protein and the availability of membrane based technologies to recover the whey protein in the past decades [11], the actual implementation of these membranes at an industrial scale was impractical as the technology was not sufficiently mature. Moreover, the economics also dictate that the cost of the membranes should be low enough for an industrial entity to recover the initial capital outflow within a reasonable period of time, i.e. relatively short payback times are required for industrial scale resource recovery operations.

TRL together with economics dictate if a resource recovery solution is ready to be commercialised. However, the actual 'real-world' implementation of these solutions requires both the technology provider and the technology receiver to collectively transfer the technology from a concept to an implemented solution. Academics involved in the development of a resource recovery solution often create spinout (startup) companies to better facilitate this technology transfer (including one of the case studies). At the same time, the transfer process requires the active participation of the industrial entity where the solution would initially be implemented. The concept of organisational readiness, management change and customer readiness level (CRL) focuses generally on this topic and illustrates the importance that customer, society and technology provider and the synergy between the three entities have in developing and implementing a solution [14-16].

While economics forces, TRL as well as intricacies of technology transfer dictate if a resource recovery solution can be commercialised now, it is important to also keep the short and long-term societal and environmental impacts of resource recovery technologies in mind. This should be done, since the concept of resource recovery is primarily addressing the long term transition from a linear economy to a circular economy [4]. The water-energy-food (WEF) nexus is one notion that can be used to put the social and environmental aspects into perspective [17]. The WEF nexus explains that there is a set of dynamic and complex interconnections between water, energy and food, that must be taken into account and managed long term [18]. The WEF is especially important when looking at resource recovery in the food processing industry as any efficiency gains in this sector will directly influence the raw material demands of the industry, while ensuring energy and other additional resources used as well as the generation of waste by- 
products does not outweigh the efficiency gains [19,20]. This type of implications has been discussed in [21] with respect to biorefinery concepts where a balance must be reached between the energy and the adjoining food and water part of the WEF nexus. While in [22], the authors discuss the resource impact in terms of the WEF nexus by reducing food waste through better food waste management practices. It is also important to note that having a resource recovery technology influencing any one pillar of the WEF nexus would also have an influence on all the other pillars. As such, expanding an otherwise WEF intensive process with any resource recovery concept, could potentially alleviate the strain of the given process. Looking at the above considerations as a whole it is apparent that transitioning a resource recovery concept working in lab scale to a commercialised solution requires the careful consideration and management of multi-disciplinary factors, particularly in managing TRL, economic factors and technology transfer aspects, while also considering the long-term WEF implications. To this end there is a need to look at this as a multifaceted problem from a process systems engineering point of view. There exists previous work where systems thinking and systems engineering concepts have been employed to tackle WEF nexus related issues. For example, the work carried out in [23] on the use of Pareto optimality and conditional-value-at-risk analysis in making multi-stakeholder decisions and conflict resolution. Work looking at the technological and logistical challenges of recovering phosphorus form livestock waste has been done as well [24]. In [25], the authors have taken a systematic look at wastewater treatment and water use in general, and explored possibilities to recovery, reuse and reduce the use of water resources. In [26], the authors take a more holistic look at the WEF nexus and propose research areas where systems engineering can make a potential impact, while in [27] the authors have applied a systematic WEF based framework to understand the grand ecological implication of bioethanol production at a state-wide level. In [28], the authors have developed a simulation tool that can be employed in understanding some of these complex interactions between the elements of the WEF nexus. As such, the concepts, tools as well as the line of thinking developed in systems thinking and systems engineering can be beneficial in putting into perspective the role of resource recovery in alleviating the strains on the WEF nexus.

The rest of this manuscript is organised as follows: In section 2, four case studies looking into different aspects of resource recovery are explored. Two of these case studies are directly related to alleviating the strain of food production and reducing the environmental impact of food production by recovering resources from waste streams. The other studies indirectly ease the strain by influencing the consumption of energy and water resources in their current form, but can be easily adapted to utilizing waste from food production as well. The case studies explored vary in the level of technology readiness (TRL of 2 to 7). Each case has been primarily chosen for its practical approach, with the focus of ultimately reaching industrial implementation. In Section 3, the implications of these case studies on the WEF nexus in general and on reducing the specific environmental impact of food production are discussed, followed by an analysis on commercialisation, where aspects such as industrial needs, the role of industrial symbiosis and the current barriers to commercialisation are discussed. In Section 4, concluding remarks are made. 


\section{Case Studies}

In this section, four industrially relevant case studies will be presented. The case studies selected are based on current work carried out at or by affiliates of the Process and Systems Engineering Center at the Technical University of Denmark, and cover the whole innovation spectrum. Where each technology fits into the WEF nexus is briefly illustrated in Figure $1 \mathrm{~A}$ and $\mathrm{B}$.

The focus in this section is to describe briefly the background of each case study with respect to its impact on the WEF nexus, and the technical innovation that has taken place to make the technology technoeconomically promising.

\subsection{Fermentation-based protein production for fish feed using keratin waste}

Keratin-rich animal by-products such as nails, feathers, horns, hooves, wool, bristles and hairs, constitute some of the most largely underexploited renewable sources of proteins [29]. Keratin waste biomass is classified as a low-risk animal by-product which occurs abundantly in slaughterhouses and meat \& poultry processing plants. Therefore, this type of solid residue is not suitable for human consumption and needs to be treated before its disposal into the environment [30,31]. In 2014, approximately 432 and $221 \mathrm{k}$-tons of wet chicken feathers and pig bristles, respectively, were generated as a waste inside the European Union (EUROSTAT 2016).

The aquaculture industry is one of the fastest growing sectors in food production, and it already accounts for production of approximately half of the seafood consumed in the world. Fishmeal constitutes one of the main ingredients of fish feed and represents about $40 \%$ of its total weight. Currently fishmeal is produced from wild fish and about one quarter of the wild fish caught each year is used as food for cultivating aquatic species, which is considered an unsustainable practice. As such, novel technologies for making proteins for feeding farmed fish are gaining importance continuously. The soluble proteins, peptides and free amino acids extracted during the enzymatic degradation of keratin could potentially supply the need for protein in fish feed, provided an economical and risk-free technology can be found. As such, the microbiological processing of keratin waste biomass can address this problem by solving it with a holistic approach, which integrates both waste remediation and resource recovery. This is completely in line with the current focus on circular economy concepts and will directly reduce the strain on the WEF nexus, as fishmeal - which is otherwise produced by unsustainable practices - can now be produced from an animal by-product.

From a technical point of view the effective reutilization of such a type of keratinous by-product constitutes an unsolved problem due to its outstanding resistance to chemical and enzymatic digestion [32]. Within the rendering industry hydrothermal treatment is the most widely applied method to process keratinous waste biomass [33,34]. Hydrothermal treatment for the production of keratin meal involves three major steps, i.e.: 1) hydrolysis; 2) drying; and, 3) grinding. During the hydrolysis step, the keratin waste is steam cooked in an autoclave employing an optimum combination of temperature $\left(\sim 130-145^{\circ} \mathrm{C}\right)$, pressure $(\sim 207-414 \mathrm{kPa})$, 
and time ( $20-150 \mathrm{~min})$ in order to hydrolyse the keratinaceous proteins [35,36]. This is actually not a real hydrolysis process but more correctly a denaturation process in which molecular constituents of the keratin structure are split, while the primary protein structure remains largely unaltered. Hydrolysis is normally followed by a drying step, during which the amount of water contained in the keratin hydrolysate is reduced to a desired level. Lastly, the dried material is ground by hammer milling to obtain a powder with an average particle size suitable for its inclusion in animal feeds. However, steam pressure-cooking of native feathers and hog hairs is an expensive process route to obtain both types of keratin protein hydrolysates, also considering the significant amounts of energy consumed during the treatment. Additionally, when hydrothermal methods are employed some essential amino acids such as cysteine, methionine and lysine are lost, while non-proteinogenic and therefore non-nutritive amino acids such as lanthionine and lysinoalanine are formed [36,37]. As a consequence, the final product is characterised by poor digestibility and low nutritional value, which considerably limits its use as ingredient for animal feed [38,39].

Recently, a novel integrated approach for the consolidated bioconversion of thermally pretreated porcine bristles into a highly digestible keratin protein hydrolysate (approximately $95 \%$ in vitro pepsin digestibility) directed by the filamentous bacterium Amycolatopsis keratiniphila D2 has been described [40]. The biotechnological strategy detailed in this work consisted of a two-stage microbial degradation process, shown in Figure 2, in which both the production of keratinolytic enzymes and hydrolysis of keratinous waste material at high solids loadings ( $16 \% \mathrm{w} / \mathrm{v})$ were conducted, in a single unit operation, under optimal conditions.

The developed method permitted to fully disengage the growth of the bacterial strain, i.e. the stage controlling the extracellular synthesis and accumulation of the keratin-specific proteases into the culture broth, from the phase in which the pretreated pig bristles were enzymatically converted into smaller soluble products (i.e., crude soluble proteins, oligopeptides and free amino acids). Therefore, since the two phases involved in the biological degradation process were fully decoupled, both stages could be optimized independently. Under the established conditions, at the end of the process, a highly concentrated $\left(89.3 \mathrm{~g} \cdot \mathrm{L}^{-1}\right.$ crude soluble proteins) keratin protein hydrolysate was obtained.

From a technology readiness level point of view the solution proposed in this study [40] is still at a low TRL range (1-3) as it has only been demonstrated at lab scale. The fact that the feedstock used in the process is actual waste from slaughterhouses allows for a realistic estimate of the potential economic benefits and streamlines a future commercialisation pathway. However, this requires the further investigation and development of the overall process (including the separation steps) and the testing of the key technologies at pilot scale.

In terms of the WEF nexus, this case study directly influences the Food pillar of the WEF as slaughterhouse waste will be transformed into raw material for fish feed. The case study in its current form, also directly reduces the environmental impact of food processing by recycling of the waste produced. 


\subsection{Production of single cell proteins from flare gas}

Flare gas is an unavoidable by-product of crude oil extraction and refining. Accumulation of natural gas when processing crude oil can cause system-wide pressure build-up, which can ultimately damage equipment and pose a serious hazard to personnel, and also to the surrounding environment. To mitigate this risk, the easiest measure to implement, is to vent the gas through a Pressure Relief Value (PRV) into a flare, and ignite it to produce carbon dioxide and avoid the release of natural gas, which is a much more potent greenhouse gas [41]. It is not a common practice for oil refineries to install mass flow meters on their safety vents, making the exact amount of flare gas difficult to quantify. However, recent estimates of flare data have been obtained through satellite imaging [42] and are displayed in Figure 3.

It is quite evident from Figure 3 that a significant amount of natural gas is flared annually. An incentive to recover this resource, and comply with the "No flaring by 2030" initiative by the United Nations [44] could be provided, if the flare gas could be upgraded to a value added product. This could be achieved by converting the flare gas to single cell protein (SCP) through a fermentation process with methanotrophic bacteria, a group of bacteria which uses methane gas, the predominant species in flare and natural gas, as the sole carbon and energy source. Methylococcus capsulatus (bath) has historically been the methanotrophic strain of choice for this process due to its high optimum growth temperature, and relatively fast growth rate ( $45^{\circ} \mathrm{C}$ and $0.37 \mathrm{~h}^{-1}$ respectively) [45]. Under ideal process conditions, the bacterial conversion of methane gas to biomass can be described by a single global stoichiometric equation (Eq. 1) $[46,47]$

$$
\mathrm{CH}_{4}+1.45 \mathrm{O}_{2} \stackrel{q_{x}}{\rightarrow} 0.52 \mathrm{X}+0.48 \mathrm{CO}_{2}
$$

In Eq. $1 X$ is the biomass, and $q_{x}$ is the rate of reaction. The process is associated with quite a few interesting chemical engineering challenges. Microbial fermentation processes require water as a solvent and have a notoriously low volumetric yield, which must be mitigated by large working volumes [45]. At a modest space-time yield of $4 \mathrm{~kg} \cdot \mathrm{m}^{-3} \cdot \mathrm{h}^{-1}$, the process would require a supply of approximately $5 \mathrm{~kg} \cdot \mathrm{m}^{-3} \cdot \mathrm{h}^{-1}$ of methane and $14.5 \mathrm{~kg} \cdot \mathrm{m}^{-3} \cdot \mathrm{h}^{-1}$ of oxygen, respectively. At the mild conditions required for the fermentation process, both methane and oxygen are present in gaseous form. Consequently, to support the bioreaction taking place in the liquid solvent (water), where the solubility of both gasses are extremely low, a large gas to liquid mass transfer rate is necessary, if the demands of oxygen and methane are to be met. Metabolic heat production is approximately equal to $460 \mathrm{~kJ} \cdot\left(\mathrm{mol} \mathrm{O}_{2}\right)^{-1}$ for aerobic fermentation processes [45], meaning that efficient heat transfer is required to remove heat equivalent to $208.6 \mathrm{MJ} \cdot \mathrm{m}^{-3} \cdot \mathrm{h}^{-1}$ from the system.

The process is immensely interesting in the context of the WEF nexus, because it is one of very few technologies that allows direct conversion of fuel into feed ingredients. The engineering challenges would 
have to be addressed, however; i.e. it would be necessary to recover the process water downstream to reduce the impact of the low volumetric yield, and to develop a reactor design that facilitates a good heat and gasliquid mass transfer to reach the desired space-time yield. The technology is being pioneered by Unibio (DK) and Calysta (USA). Unibio recently opened a commercial plant in Russia [48] while Calysta operates a market introduction plant at Teeside, UK [49]. Both companies utilize unconventional loop bioreactors[46] to achieve a high heat and gas-to-liquid mass transfer. A picture of a loop reactor can be seen in Figure 4.

As a result of these commercial efforts the TRL of this technology is in the medium-high range (5-7), which means that the economic and environmental factors would be the principal considerations in achieving widespread commercialisation of the technology.

In terms of the WEF nexus, this case study influences the Food pillar by taking waste methane from the energy pillar as it is transformed into single cell protein (SCP), which can be used as a raw material in farming practices. As such, the case study in its current form reduces the environmental impact of food processing by reducing the raw material demand of food production.

\subsection{Valorization of waste streams for biobutanol production}

Butanol produced from renewable bio-based sources (biobutanol) is a promising biofuel with ideal properties to replace petrol-based transport fuels on a large scale [50,51]. It has a 50\% higher energy density than ethanol, which is used as fuel additive nowadays, and allows blending with gasoline in any proportion $[52,53]$. The volumetric energy density of liquid biofuels is almost 100 times higher than that of current electrochemical storage devices and this significant advantage is expected to last for decades, even when considering the latest progress in battery capacity [54]. Therefore, biobutanol can make a significant contribution to sustainable road transport and aviation, especially when electrical alternatives fail to meet the required performance characteristics. Beyond that, butanol is a widely used commodity chemical. It is used as solvent, extractant and precursor chemical in many industries, ranging from coatings to cosmetics [50]. Butanol can be produced via the petrochemical route or through microbial fermentation. In the latter case, it is often termed biobutanol. The established route for biobutanol formation is acetone-butanol-ethanol (ABE) fermentation [55,56] Industrial biobutanol production experienced its rise during World War I and was followed by a growing interest in butanol for the manufacture of lacquer. After World War II, however, the petrochemical route became more profitable. Molasses, the key substrate of ABE fermentation, faced a growing demand from emerging markets and suffered a severe price escalation. The ABE process became economically unattractive in Western countries. Nevertheless, ABE fermentation remained viable in South Africa until 1981 due to the local abundance and cheap supply of molasses. In recent years, biobutanol has seen renewed interest as societies strive to establish improved resource recovery and carbon-neutral production. 
The example of ABE fermentation highlights the importance of a constant and cheap substrate supply for biobutanol production. Waste streams from the food and beverages industry can fulfil both criteria. In particular, waste streams from distilleries and breweries are marked by a high chemical (COD) and biological oxygen demand (BOD), and low pH [57]. These conditions are beneficial for butanol formation, whereas high-strength wastewater is typically regarded a financial and organizational burden by plant operators since acceptable discharge limits must be ensured [58]. A waste-to-value activity such as coupling butanol recovery to plant effluents can have a double impact on the operator's bottom line. Plant operators can reduce sewer discharge fees and eliminate BOD surcharges, while recovering a valuable side product and reclaiming fresh water.

$\mathrm{ABE}$ fermentation is typically performed with pure strains that cannot operate on complex waste streams [59]. These pure cultures, often Clostridia species, require expensive sugary substrates and sterile operating conditions. Genetically engineered strains have been reported to produce higher butanol titers [60], but these require the same sterile operating conditions. Moreover, they are prone to functional loss and subject to strict regulation [52]. Anaerobic mixed microbial cultures (MMC) offer an attractive solution to these challenges. MMC biotechnology engineers the environment rather than the microorganism with the goal of finding operating conditions that enrich species of desired metabolic function [61-63]. Successful application of MMC technology for the production of biodiesel, bioplastics and caproate substantiate the effectiveness of the approach [64-67]. On-going research by the authors aims to establish continuous butanol production from butyrate and hydrogen using mixed microbial consortia. This process is inspired by the anaerobic digestion process, an established wastewater treatment technology in which different microbial groups degrade complex organic matter into biogas [68-71]. Butyrate and hydrogen are key metabolites in anaerobic digestion, and butanol can be formed directly from these substrates. By increasing the hydrogen partial pressure and lowering the $\mathrm{pH}$, a new operating regime can be defined that favors reduced product formation from volatile fatty acids, including the formation of alcohols such as butanol (see Figure 5). These conditions provide a new perspective to anaerobic digestion as value-added liquid fuels can be recovered aside from biogas.

Experimental studies provide evidence for butanol production using MMC technology. The production of several alcohols including methanol, ethanol, propanol and butanol from lactose was demonstrated in an upflow reactor and through batch cultivation $[72,73]$. These results show the potential for butanol recovery from dairy processing effluents. Butanol production was also reported in an ethanol-perturbed continuously stirred tank reactor fed with butyrate and ethanol using MMCs [74]. In that study, bicarbonate limitation caused a shift from methane production towards butanol formation. Finally butanol formation in MMCs under batch conditions using butyrate and hydrogen as the sole substrates has been reported [75]. Methane was a major by-product. Several Clostridia species are known to produce butanol from butyrate and hydrogen with strict glucose requirement $[52,76]$. Clostridia are natural inhabitants of the wastewater ecosystem [59]. Therefore, it remains a matter of shaping the process conditions to promote butanol production in such microbial communities. 
MMCs help to overcome several key challenges related to pure culture technology. They can cope with nonsterile waste streams of varying composition and load. The adaptive capacity to changing waste streams adds to stable process economics. On the one hand, MMC technology lowers the economic dependence on a single feedstock, as was the case with molasses for ABE fermentation. On the other hand, an increased product spectrum spreads the risk for price fluctuations in the downstream markets. Eventually, MMCs hold promise to become a key technology in the biorefinery concept, which promotes a range of value-added biofuels (e.g. C2-C6 alcohols) and energy-rich chemicals (C6-C8 fatty acids) on the basis of generic process intermediates (e.g. volatile fatty acids) [77,78]. Realizing butanol production from waste streams can be a major step towards achieving this goal. However, on the path to full exploitation of MMC biotechnology, several challenges have to be addressed. For example, butanol is cell-toxic which is limiting the butanol titre [55,59]. Current research is investigating improved separation technologies for in-situ product removal (e.g. gas stripping or membrane separation) to alleviate such effects [79]. Once these obstacles are resolved, waste-sourced biobutanol can make a vital contribution to a more balanced water-energy-food nexus in our communities.

In terms of technology readiness the MMC production is currently at a low TRL range (1-3) as the experiments are only performed at lab scale. However, the potential economic benefits of this work are due to the ability of the technology to operate without the need for costly chemical pretreatment of the waste streams. In this case study, the MMC influences the energy pillar by taking waste generated in the water pillar of the WEF nexus by converting waste streams into biobutanol. However, MMC technology can be adapted to take waste streams from food production and generate biobutanol which would reduce the environmental impact of food production.

\subsection{Recovery of energy and nutrients in traditional wastewater treatment systems}

In light of the increasing demand for water and energy and their associated costs, the scientific community is changing the vision of wastewater treatment from the traditional "out-of-sight, out-of-mind" approach towards considering raw wastewater as a source of valuable resources. Nutrients, such as phosphorus $(\mathrm{P}) \mathrm{can}$ be recovered in various forms for use in agriculture as slow-release fertilizers [80]. On the other hand, energy in the form of heat and electricity can be extracted from organics to reduce the power demands of the treatment facility without compromising the efficiency of treatment as far as effluent quality is concerned [81]. Therefore, the research/engineering community is facing a transition from conventional wastewater treatment plants (WWTPs) into water resource recovery facilities (WWRFs) [82].

Along this line of thinking, a holistic approach is required for handling energy and nutrient fluxes within the different sub-systems comprising the flow diagram WWRFs have been proposed to enable the evaluation of their potential recovery. Indeed WWRFs should be considered as an integrated process, where primary/secondary clarifiers, activated sludge reactors, anaerobic digesters, thickeners/flotation units, 
dewatering systems and storage tanks are linked tightly together and need to be operated and controlled not as individual unit operations and processes, but taking into account all their potential interactions [83]. This case study evaluates the development of resource recovery alternatives in a WWTP located in South East Queensland which was designed for removal of organic matter (COD), $\mathrm{N}$ and $\mathrm{P}$ from domestic wastewater of approximately 750000 person equivalent. To this end, a plant-wide model is constructed according to the principles reported in the Benchmark Simulation Model No. 2 (BSM2) describing the main interactions between the water and the sludge line[84]. The model, applied to the full-scale WWTP, is calibrated and is used as a baseline scenario $\left(\mathrm{WWTP}_{0}\right)$ (see Figure 6). Several recovery alternatives (WRRF $\mathrm{W}_{1}$, $\mathrm{WRRF}_{2}$ ) are implemented, simulated and evaluated using process simulation. Changes in the Effluent Quality and Operational Cost are quantified as a consequence.

In the first scenario $\left(\mathrm{WRRF}_{1}\right)$, the efficiency of the primary settler is modified assuming chemically enhanced primary treatment (CEPT) using iron chloride $\left(\mathrm{FeCl}_{3}\right)$ as precipitant according to [85].). The iron precipitation model is based on the principles stated in [86] and Sumo2S (www.dynamita.com). The second alternative $\left(\mathrm{WRRF}_{2}\right)$ focuses on maximizing nutrient recovery in the form of struvite from the anaerobic digester supernatants. The latter modifies the original plant layout by adding a crystallizer to facilitate controlled and enhanced struvite recovery, a magnesium $\left(\mathrm{MgOH}_{2}\right)$ and sodium hydroxide $(\mathrm{NaOH})$ dosage tank and a dewatering unit to facilitate $\mathrm{P}$ recovery. These units are modelled according to [87]. The options evaluated in this case study have been systematically generated, but they are based on general process knowledge.

From an environmental point of view, the proposed alternatives $\left(\mathrm{WRRF}_{1}, \mathrm{WRRF}_{2}\right)$ result in improvements with respect to the open loop default configuration WWTP $P_{0}$. The main reason is that $\mathrm{WRRF}_{1}$ and $\mathrm{WRRF}_{2}$ substantially reduce the quantity of $\mathrm{P}$ that is discharged via the effluent. The higher quantity of organics arriving to the anaerobic digester increase methane production and therefore energy recovery i.e. the facility has installed a co-generation unit. Nevertheless, the periodic purchase of iron salts for P precipitation in $\mathrm{WRRF}_{1}$ substantially increases the plant's operational expenses. The potential modification of the plant layout promoting $\mathrm{P}$ recovery results in the best economic numbers even though the results of this evaluation should be taken with care. Firstly, capital costs of the crystallizer, civil, electrical and piping works should be included in order to make a more complete assessment of $\mathrm{WRRF}_{2}$. Secondly, the financial benefits coming from struvite are very uncertain [88]. It is also important to note that the operational and structural changes carried out to the plant should be carefully and systematically considered. To this end the methodologies outlined in [89] can be used. Proper assessment methodologies could be included to have a better idea of existing synergies and trade-offs [90].

In terms of TRL, the structural and operational changes carried out during this case study are already industrially available, and as such a high TRL range (7-8) can be assigned to the proposed solution. As such, the implementation of the $\mathrm{WWTP}_{2}$ plant layout, which is the most economically lucrative alternative, would 
be purely an economic and environmental decision. In this case study the changes to the WWTP influence the energy pillar by taking waste generated in the water pillar of the WEF nexus by converting wastewater into produced energy, while also recovering additional nutrients that can be used in agriculture which will affect the food pillar. However, similar modification and the concept of an advanced WWTP in general can be used to take wastewater streams from food production and generate energy and nutrients for agriculture, which would directly reduce the environmental impact of food production.

\section{Implications and Commercialisations}

In section 2, four case studies were presented which influence the WEF nexus as well as food production. The case studies presented cover a diverse range of TRL and levels of aggregation as illustrated in Figure 7. For instance, both the keratin conversion process and biobutanol production are at TRL range of 1-3 and are currently focusing on understanding the phenomena which govern the process. In contrast, SCP production at a TRL range of 5-7 is focused on developing pilot and full-scale technology solutions based on the existing understanding of the phenomena, while the WWTP example with a TRL range of 7-8 is carrying out changes in operation and addition of equipment on an established commercial process.

The case studies covered in section 2 are also diverse in their impact on resource usage in industrial scale food production processes as illustrated in Figure 1. Keratin production in this instance stays within the food pillar of the WEF nexus where it improves the resource usage through recovering proteins, which would otherwise be treated as waste. While the SCP production affects the energy and food pillar where waste methane gas (used for energy) is used as raw material for the production of protein rather than being flared. The produced SCP is then used as a raw material in food production. The WWTP influences all three pillars of the nexus and each specific case study illustrates how changes in WWTP operations and structure can be used to produce more energy and/or recover nutrients while also recovering water that can potentially be treated further for reuse. In this instance the nutrients recovered, such as phosphorus, can be directly used as raw materials to support agricultural production, thereby reducing the strain on food production. Moreover, the extra energy recovered together with the water indirectly relieves the strain on the food pillar by affecting the water and energy pillars. Biobutanol production from wastewater is currently a part of the water and energy pillar where wastewater is used to produce biobutanol, which can be blended with gasoline as an energy source, as such indirectly influencing the food pillar through the WEF nexus.

Focusing specifically on the direct reduction of waste from food production, one can observe that the technologies used for biobutanol production as well as the WWTP case study can also take food waste (solid/wastewater) as feedstocks. As such, from a technology point of view, biobutanol can operate within the food water nexus where food waste can be transformed into an energy carrier while the WWTP can transform food waste (wastewater) into clean water (influencing the water food nexus). Taking these possibilities into account, the technologies highlighted in the case studies can be used to transform food waste into valuable products, which also reduces the overall environmental footprint of the products. So far, 
the focus of this manuscript has been on holistically identifying the needs and benefits of resource recovery, and also detailing the technical aspects of four case studies which can potentially realise these benefits. However, the realisation of these benefits inevitably requires the commercialisation of the technologies discussed in the case studies. To this end, the following subsections focus on understanding the key needs of industry, the role of industrial collaboration and the current hurdles and barriers that need to be overcome to transform solutions developed into fully commercialised solutions.

\subsection{Industry needs}

Understanding the needs of an industrial partner or customer can be complicated as they may have multiple requirements. However, according to our opinion and experience the following two aspects hold the key in identifying promising commercialisation opportunities.

\subsubsection{Value proposition}

From an industrial point of view a key yard stick for measuring the importance of a project is its value proposition. The value proposition in resource recovery in general - and in the case studies specifically - is their ability to recover and/or convert otherwise invaluable resources into products that are of value. This value proposition is further augmented by the fact that these resource recovery technologies alleviate the strain on the WEF nexus of an industrial food producer. However, the specific value proposition for a given case study would change from implementation to implementation. For example, the value proposition of the SCP production as described in section 2.2 is greater near an oil field. But in principle, the SCP production can also be combined with a biogas production plant to transform methane obtained from digestion of a waste stream to valuable protein. Similarly, the production of fish feed from keratin has a higher value proposition at a slaughterhouse. Biobutanol production would have a high value proposition in situations where hydrogen can be obtained at reduced cost, such as in a crude oil refinery where a continuous catalytic reformer produces more excess hydrogen that cannot be consumed within the refinery [91], or next to a power plant where excess power can be converted to hydrogen during night time. As such, from a commercialisation point of view it is important for a given technology to be paired with a situation where it has the highest value proposition. This determination can be made by using Net Present Value (NPV) based concepts as outlined in [92,93]. It is also important in some situations to analyse multiple alternative solutions as well as the cost/benefit of carrying on business as usual. To this end, the differential NPV based analysis outlined in [89] can be used for comparison and selection purposes.

\subsubsection{Ease of Implementation}

Ease of implementation is another key attribute that must be considered when commercialising any technological solution. Resource recovery in general has one key advantage in this regard, as it can often be 
implemented as a standalone solution that does not affect the main production process. In contrast, proposing a paradigm shift in food production processes to incorporate the resource recovery process itself, will potentially yield a reduced environmental footprint, but requires large investments, long lead times, and investments in repurposing and adding new plant equipment. Therefore, the resource recovery solutions proposed here are more attractive since they can be implemented within a short time period as an add-on to existing processes with comparatively low levels of development and implementation costs.

In terms of the case studies, the non-invasive standalone aspect is true for keratin, SCP and biobutanol production. As such, there are no risks that are introduced to the main process if these implementations do not perform up to expected standards. For energy and nutrient recovery from a wastewater treatment plant this may not be valid (assuming the wastewater treatment plant is the main production/operation). In this case, the concepts outlined in [89] can be employed in putting these risks into perspective and developing solutions to manage them.

Looking at the biobutanol production case study in detail, it can also be seen that the approach taken despite being of a relatively low TRL - inherently takes into account the fact that the feedstock to the process can be contaminated with other microorganisms. Addressing this requirement from an early stage of the development process means that the implementation of such a concept would be more robust as opposed to the development of a technology which does not take this aspect into account.

\subsection{Industry-academia collaboration}

One key aspect that is necessary for commercialising promising ideas developed in academia is the periodic and continued involvement of industrial entities. This is the case for all four case studies discussed, with the SCP production currently transitioning into a self-sustaining commercial entity under the company Unibio. In Denmark (as well as in other countries), funding agencies such as the EU, Innovation Fund Denmark and private foundations such as the Novo Nordisk Foundation, support applied research and are increasingly emphasising the requirement to involve industrial entities to better align the academic development and industrial needs. This is for the purpose of creating novel solutions that can potentially be developed into commercial solutions with relative ease, compared to purely academic technologies and solutions.

In Denmark, as an example, this requirement for close collaboration between academia and industry has resulted in the creation of organisations such as the BIOPRO strategic research consortium [94,95]. The BIOPRO Strategic Research Centre (www.biopro.nu) was established with the explicit aim of promoting collaboration between academia and industry. Large Danish biotech manufacturers (Novo Nordisk, Chr. Hansen, Novozymes, CP Kelco, Xellia Pharmaceuticals), in most cases world leaders in their industry, work together with the Technical University of Denmark and The University of Copenhagen with the aim of developing innovative industrially applicable solutions for improving bio-based production processes [94,95]. As a result of BIOPRO: 
- Academic and industry partners can freely share information under a general non-disclosure agreement

- Academic partners get to try and shape their scientific innovation based on real world information provided by the industrial partners on the basis of their production processes

- Academic partners can test their solutions from an early stage on industrial systems or pilot facilities run by industry

- Industry partners get updated with the state-of-the-art developments carried out in academia and have the ability to try out novel process solutions

- Industry partners have the benefit of being first movers on promising economic solutions

Once a promising solution is developed and proven at lab scale, the BIOPRO collaboration framework allows for the creation of start-up companies, which are used to commercialise the solutions. Since the startups are created within the BIOPRO framework, they have a more streamlined NDA/approval process with the industrial partners, also using the industrial partners as first customers for the developed technology.

One such start-up that emerged from the BIOPRO consortium is BioScavenge ApS (www.bioscavenge.com), which deals with recovery of valuable compounds from industrial process waste streams, as well as with purification of industrial streams in order to make them suitable for release in the environment. BioScavenge Aps has carried out several pilot scale studies with the main focus on recovery of valuable small and large organic molecules, as well as organic solvents and water. It's processes have been tested successfully under the academic Good Lab Practice (GLP) conditions for small scale recoveries, as well as under the industrial Good Manufacturing practice (GMP) environments for large scale processes (from $500-2000 \mathrm{~L} / \mathrm{hr}$ scale). The company is currently preparing for the first full-scale process that is planned to be fully operational in 2020.

\subsection{Barriers to success}

While understanding the industrial needs and getting industrial partners engaged throughout the development process holds the key to successful commercialisation, there are many important barriers that must also be overcome in the arduous journey from transitioning a technology/scientific novelty to commercial success. While these barriers can also be found in other technology development/commercialisation projects, they nonetheless dictate the difference between success and failure of a given resource recovery project in the domain of food production. Some of the key barriers faced are summarised below:

\subsubsection{The cost of technology development}

The cost of developing a resource recovery technology from lab scale to pilot scale and finally to industrial scale increases exponentially [96]. For example, only 12-26\% of the total cost of technology development 
maybe used in developing a resource recovery technology from TRL 1 to 4 [96]. This is mainly due to the fact that there is a significant amount of engineering work that must be done to first turn a lab scale scientific demonstration into a pilot scale demonstration. Furthermore, important factors explaining these numbers are also the augmented costs of running pilot scale equipment in terms of material and energy usage in comparison to lab scale experiments, and the cost of capital involved in building full scale resource recovery plants.

In pilot scale, the cost of technology development can be somewhat reduced by co-financing technology development through government programs (EU and regions) that are in place to fund this stage of development. For example this type of co-financing has supported both Bioscavenge Aps as well as SCP production company Unibio with the development of their technologies. To reduce the cost of development, Bioscavenge Aps has adopted the use of modular solutions that can be parallelized during full scale operations, which significantly reduces the initial capital required to build full scale solutions. As such, the application of modular solutions where practically feasible can reduce the development cost as opposed to a full scale solution. To reduce the cost of experimentation, a state-of-the-art validated process model can be of use as simulation studies may substitute some of the pilot and full scale experimental work. For example this has been the case in the WWTP case study while the SCP production example also uses simulations to cut down on the number of pilot scale experiments that are required.

\subsubsection{Implementation and operations Risk}

Industry in general is highly risk averse toward the implementation of new types of process technologies including resource recovery technologies. This can be both due to actual and perceived risks that implementing a new technology may result in reduced throughput and/or the perception that any benefits gained during routine process operations will be nullified due to a non-routine process breakdown [89]. As such, industry always prefers to use the most established and simplest possible solution rather than trying out a novel yet more efficient solution unless there is a need for a change. It is also important to note that for resource recovery units which are usually dealing with waste resources this perceived economic risk is somewhat lower, as the economic cost of a process break down is not as high in comparison with a technology that is part of the main production line.

In general, industries are prompted to overcome this barrier because of economic or regulatory reasons. For example if the economic benefits of a given technology change is significant enough to force industry to adopt it, i.e. not adopting it will weaken an industry in view of global competition. This was the case in the use of membrane technology to recover whey protein, as not recovering the whey protein would make the bottom line of a dairy production facility much less attractive [10]. Similarly, this barrier can also be overcome when health/environmental policy forces an industry to make changes,

In the SCP process, the pilot scale set up acts as a technology demonstrator which reduced the perceived technology risk. Similarly the demonstration of a concept of a validated process simulation can also aid with 
managing the perceived technology risk such as done in the WWTP. For resource recovery solutions such as the ones discussed in this study the perceived economic risk can also be reduced significantly just by keeping the current method of waste treatment active and available during the initial implementation. This is because any failure in the resource recovery technology will not affect the production process as the current waste treatment method serves as a backup.

\subsubsection{Intellectual property and confidentially}

Many resource recovery technology development projects can trace their origin back to some kind of industrial-academic collaborative work where the initial scientific concept has been developed; this is true for the SCP, WWTP, the keratin extraction case studies as well as the BIOPRO start-up Bioscavenge. To this end both the academic and industrial partners will collaborate and share data from an early stage of process development onwards. As such there is a need to clarify early on both intellectual property rights and confidentiality issues that may arise from such a close collaboration.

This is especially of concern when the work carried out jointly needs to be presented or published by the academic partner such as when post graduate students are involved and the work is not considered "pure" consulting work. At the same time the industrial partner (To be more specific the intellectual property and/or public affairs department of the industrial partner) would often prefer to keep the work confidential. These confidentiality issues also apply to resource recovery development, but in general for resource recovery the industrial partners are more forthcoming with information related to the processing of waste streams as opposed to providing information about the main process. However, in some instances strict non-disclosure policies apply to the waste stream information, as detailed information about the content of the waste streams can be used to gain insights into the main production process. In [93], the authors tackled this need for confidentiality by labelling the industrially sensitive components as "other compounds" as they had no influence on the subsequent analysis of the work. The use of industrially validated simulations can also enable the publication, where phenomena can be observed and concepts demonstrated without revealing sensitive industrial plant data, as done by some of the authors involved with this work in the field of fine chemicals separation [97-99].

Any intellectual property right that may arise from a joint process development venture between industry and academia has to be managed and agreed upon in detail ahead of time. This endeavour is somewhat simplified in resource recovery technology as many food manufacturing entities do not consider resource recovery as a core business competence and hence do not want to develop the initial lab scale/pilot scale technology into a commercial product. At the same time academic institutions do not have the resources, the mandate or the expertise to transition lab/pilot scale technologies into commercial products. As discussed in section 3.2, creating spin-out companies from these types of collaboration exercises can be one method of commercialising these findings and development. 


\subsubsection{Funding and technical know-how}

As discussed in section 3.3.2, for resource recovery technologies the most plausible road to commercialisation is through a start-up / spin out. While government programs (EU and regions) are in place to fund this stage of development, the amount of funds available to start-ups is both capped and subject to securing private investors such as venture capital. This creates a unique dilemma for chemical engineering start-ups as venture capitalists like to put a heavy discount on the value of a technology which has not been "implemented", while the start-ups require significant investments to demonstrate capabilities at pilot scale (TRL 6) and beyond. As such a "Chicken and Egg" funding situation can result, where the very capital that is needed for the demonstration of the process at full scale requires the technology to be developed to full scale prior to the funds being released. However, one positive aspect of resource recovery technologies that may attract investment is their broad spectrum of applicability as waste generated in biotechnology as well as food manufacturing processes can be somewhat similar to each other.

Another key aspect that needs to be managed in the latter stage of technology development is getting individuals with the necessary technical skills involved as the development of a process from TRL 6 to implementation requires an ever increasing involvement of practicing industrial engineers as opposed to research engineers who develop the concept up to TRL 5. Not recognising the fact that a different set of skills are required in the final stage can lead to promising technologies not reaching commercialisation. For example the SCP production company Unibio currently employs a mixture of research and technical engineers in their operations while BioScavenge Aps has commercial partnerships with technical engineering firms. Similarly a strong management core must also be assembled for the TRL 6 to implementation development stages as the budget, market risks; stakeholder expectations (investors and launch customers) and technology risks must be carefully managed.

\subsubsection{Legislation}

Government policy towards the development, implementation and operation of resource recovery technologies has a broad influence on all barriers described above. It is important to note that the support given to commercialise a resource recovery technology by a given government is different. For example governments in developing Asia cannot give the same amount of financial or political support as a government in a European nation [2]. While the authors of this manuscript are not policy experts, the authors believe that the following type of policies may be beneficial in commercialising resource recovery technologies.

I. Legislation on industry to adopt more stringent waste treatment standards

II. Preferential tax treatment for resource recovery related projects both in development, implementation and operation

III. Government funding specifically allocated towards the TRL 6-9 development of resource recovery technologies with a focus on supporting resource recovery start ups 
IV. Specific funding calls focusing on the development of industrially relevant resource recovery technologies, which require industrial, academic and start-up project partners.

\subsubsection{Logistics and Certifications}

Prior to establishing full scale operations of a resource recovery concept, it is important to address potential logistical challenges. In many resource recovery solutions this can be somewhat complex as the required feedstock (waste stream) is distributed and only available in smaller quantities. Other than the WWTP example, all other case studies must consider the logistics of securing feedstock for its processes to sustain full scale operations. However, in keratin hydrolysate production this problem is somewhat negated as the feedstock to these processes is generally waste from industrial scale slaughterhouses. This is also the case if resource recovery is attempted at food production plants. To this end, waste stream from a food production plant might be the ideal feed stock for the bio-butanol case study. In the SCP there exists a logistical challenge for securing sufficient feedstock as individual flare lines in refining and upstream operations are insufficient to support a full scale SCP production process. This can be somewhat overcome by designing smaller modular platforms.

The sale of products generated at a full scale resource recovery operation can also be a logistical challenge. This is because, at full scale, these processes may produce a large quantity of a product that then must be introduced to the relevant market. However, if the compound recovered is a specialty chemical [4] or the market for the given product is small, finding the right channels of selling these products can be complex. In the WWTP and biobutanol examples this may be a straightforward process as both struvite and butanol are commodity chemicals and as long as the necessary specifications are met they can be sold on to bulk chemical resellers. In the keratin and SCP processes, the recovered product can be sold to animal feed production processes as feedstock.

Both the equipment used and products recovered in a resource recovery solution requires certifications for full scale operations. In terms of equipment this is generally safety and environmental certifications to ensure that the equipment used for the resource recovery operations is safe to operate at given conditions. Similarly products recovered through the resource recovery operations must also be certified for the intended purpose be it commodity chemicals, pharmaceutical ingredients or animal feed. In terms of equipment all four case studies must comply with safety and environmental standards. For the biobutanol and SCP case study the process safety aspect must be considered even at pilot scale, and managed at full scale, as both processes use flammable gasses. With respect to product certification the SCP and keratin production process would have a higher level of scrutiny in comparison to bulk chemicals produced in the biobutanol and WWTP case. Moreover, if the recovered product was to be reintroduced as pharmaceutical or food grade ingredients, the level of scrutiny would further increase as for example experienced by Bioscavenge Aps. As such this complexity needs to be taken into account and managed.

\section{Conclusions}


This manuscript took a critical look at how resource recovery technologies can be used to reduce the overall environmental impact of food processing. To this end, four case studies were introduced which are either directly or indirectly alleviating the overall environmental impact of food processing. The case study on the production of fish feed from keratin directly alleviates the food waste problem by converting slaughterhouse waste into fish meal while the SCP production takes waste energy and transforms it into protein to be used as a raw material in food production. The case studies of biobutanol production and the WWTP affect the WEF nexus and by proxy the environmental impact of food production. It is also important to note that both biobutanol and WWTP processes can be applied directly on industrial food waste to produce energy and clean water respectively, which also reduces environmental impact of industrial food production. To realise the potential of these technologies, it is necessary to commercialise them. Understanding industrial needs, specifically the concept of value proposition and ease of implementation together with the need for involving industrial partners throughout the innovation spectrum, was identified as key for successful commercialisation. Nevertheless, the general risk awareness of industrial partners, the challenge of raising private equity and the confidentiality of industrial data are key barriers that need to be overcome.

\section{Declaration of interests}

$\bigotimes$ The authors declare that they have no known competing financial interests or personal relationships that could have appeared to influence the work reported in this paper.

$\square$ The authors declare the following financial interests/personal relationships which may be considered as potential competing interests:

\section{Acknowledgements}

The authors wish to acknowledge the support obtained from the Carlsberg Foundation (grant agreement CF17-0403), the European Union's Horizon 2020 research and innovation programme under the Marie Sklodowska-Curie grant agreement number 713683 (COFUNDfellowsDTU), the Danish Council for Independent Research in the frame of the DFF FTP research project GREENLOGIC (grant agreement No. 7017-00175A). Furthermore, we wish to acknowledge the support of EU's Regional fund (BIOPRO-SMV project) and Innovation Fund Denmark that has supported the Keratin2Protein project (grant agreement No. 1308-00015B), together with Unibio the Industrial PhD grant (grant agreement No. 5189-00023B) of Leander A.H. Petersen, the REWARD project (grant agreement No. 1308-0027B) and Watintech-JPI 196. We also wish to acknowledge BIOPRO2 Strategic Research Center (grant agreement No. 4105-00020B). We also wish to acknowledge 


\section{Bibliography}

[1] S.S. Mansouri, I.A. Udugama, S. Cignitti, A. Mitic, X. Flores-Alsina, K.V. Gernaey, Resource recovery from bio-based production processes: a future necessity?, Curr. Opin. Chem. Eng. 18 (2017). doi:10.1016/j.coche.2017.06.002.

[2] D.S. Gunarathne, I.A. Udugama, S. Jayawardena, K. V. Gernaey, S.S. Mansouri, M. Narayana, Resource recovery from bio-based production processes in developing Asia, Sustain. Prod. Consum. 17 (2019) 196-214. doi:10.1016/j.spc.2018.11.008.

[3] L.A. Pfaltzgraff, M. De bruyn, E.C. Cooper, V. Budarin, J.H. Clark, Food waste biomass: a resource for high-value chemicals, Green Chem. 15 (2013) 307. doi:10.1039/c2gc36978h.

[4] I. Udugama, S. Mansouri, A. Mitic, X. Flores-Alsina, K. Gernaey, Perspectives on Resource Recovery from Bio-Based Production Processes: From Concept to Implementation, Processes. 5 (2017) 48. doi:10.3390/pr5030048.

[5] R. Ravindran, A.K. Jaiswal, Exploitation of Food Industry Waste for High-Value Products, Trends Biotechnol. 34 (2016) 58-69. doi:10.1016/j.tibtech.2015.10.008.

[6] A. Yousuf, F. Bonk, J.R. Bastidas-Oyanedel, J.E. Schmidt, Recovery of carboxylic acids produced during dark fermentation of food waste by adsorption on Amberlite IRA-67 and activated carbon, Bioresour. Technol. 217 (2015) 137-140. doi:10.1016/j.biortech.2016.02.035.

[7] G. Daufin, J.-P. Escudier, H. Carrère, S. Bérot, L. Fillaudeau, M. Decloux, Recent and Emerging Applications of Membrane Processes in the Food and Dairy Industry, Food Bioprod. Process. 79 (2001) 89-102. doi:10.1205/096030801750286131.

[8] OECD, OECD-FAO Agricultural Outlook 2018-2027, OECD, 2018. doi:10.1787/agr_outlook-2018-en.

[9] Shell, The Petroleum Handbook 6th Edition, Elsevier, 1986.

[10] G.W. Smithers, Whey and whey proteins-From "gutter-to-gold," Int. Dairy J. 18 (2008) 695704. doi:10.1016/j.idairyj.2008.03.008.

[11] A.L. Zydney, Protein Separations Using Membrane Filtration: New Opportunities for Whey Fractionation, Int. Dairy J. 8 (1998) 243-250. doi:10.1016/S0958-6946(98)00045-4.

[12] Technology Readiness Level, NASA. (2012).

[13] J. Rybicka, A. Tiwari, G.A. Leeke, Technology readiness level assessment of composites recycling technologies, J. Clean. Prod. 112 (2016) 1001-1012. doi:10.1016/j.jclepro.2015.08.104.

[14] B.J. Weiner, A theory of organizational readiness for change, Implement. Sci. 4 (2009) 67. doi:10.1186/1748-5908-4-67.

[15] E. Beddewela, C.E. Warin, J. Anchor, Institutionalizing Responsible Management Education: A Change Process Model, Acad. Manag. Proc. 2015 (2015) 14185-14185. doi:10.5465/AMBPP.2015.14185abstract.

[16] S. Ho, Y. Ko, Effects of self-service technology on customer value and customer readiness, Internet Res. 18 (2008) 427-446. doi:10.1108/10662240810897826.

[17] A. Endo, I. Tsurita, K. Burnett, P.M. Orencio, A review of the current state of research on the water, energy, and food nexus, J. Hydrol. Reg. Stud. 11 (2017) 20-30. doi:10.1016/j.ejrh.2015.11.010. 
[18] M. Covarrubias, The nexus between water, energy and food in cities: towards conceptualizing socio-material interconnections, Sustain. Sci. (2018). doi:10.1007/s11625018-0591-0.

[19] R. de C. Sobrosa Neto, I.I. Berchin, M. Magtoto, S. Berchin, W.G. Xavier, J.B.S.O. de A. Guerra, An integrative approach for the water-energy-food nexus in beef cattle production: A simulation of the proposed model to Brazil, J. Clean. Prod. 204 (2018) 1108-1123. doi:10.1016/j.jclepro.2018.08.200.

[20] T. Silalertruksa, S.H. Gheewala, Land-water-energy nexus of sugarcane production in Thailand, J. Clean. Prod. 182 (2018) 521-528. doi:10.1016/j.jclepro.2018.02.085.

[21] E. Martinez-Hernandez, S. Samsatli, Biorefineries and the food, energy, water nexus towards a whole systems approach to design and planning, Curr. Opin. Chem. Eng. 18 (2017) 16-22. doi:10.1016/j.coche.2017.08.003.

[22] K.M. Kibler, D. Reinhart, C. Hawkins, A.M. Motlagh, J. Wright, Food waste and the foodenergy-water nexus: A review of food waste management alternatives, Waste Manag. 74 (2018) 52-62. doi:10.1016/j.wasman.2018.01.014.

[23] A.W. Dowling, G. Ruiz-Mercado, V.M. Zavala, A framework for multi-stakeholder decisionmaking and conflict resolution, Comput. Chem. Eng. 90 (2016) 136-150. doi:10.1016/j.compchemeng.2016.03.034.

[24] A.M. Sampat, E. Martín-Hernández, M. Martín, V.M. Zavala, Technologies and logistics for phosphorus recovery from livestock waste, Clean Technol. Environ. Policy. 20 (2018) 15631579. doi:10.1007/s10098-018-1546-y.

[25] I.O. Uribe, A. Mosquera-Corral, J.L. Rodicio, S. Esplugas, Advanced technologies for water treatment and reuse, AIChE J. 61 (2015) 3146-3158. doi:10.1002/aic.15013.

[26] D.J. Garcia, F. You, The water-energy-food nexus and process systems engineering: A new focus, Comput. Chem. Eng. 91 (2016) 49-67. doi:10.1016/j.compchemeng.2016.03.003.

[27] D.J. Garcia, B.M. Lovett, F. You, Considering agricultural wastes and ecosystem services in Food-Energy-Water-Waste Nexus system design, J. Clean. Prod. 228 (2019) 941-955. doi:10.1016/j.jclepro.2019.04.314.

[28] E. Martinez-Hernandez, M. Leach, A. Yang, Understanding water-energy-food and ecosystem interactions using the nexus simulation tool NexSym, Appl. Energy. 206 (2017) 1009-1021. doi:10.1016/j.apenergy.2017.09.022.

[29] A. Shavandi, T.H. Silva, A.A. Bekhit, A.E.-D.A. Bekhit, Keratin: dissolution, extraction and biomedical application, Biomater. Sci. 5 (2017) 1699-1735. doi:10.1039/C7BM00411G.

[30] T. Korniłłowicz-Kowalska, J. Bohacz, Biodegradation of keratin waste: Theory and practical aspects, Waste Manag. 31 (2011) 1689-1701. doi:10.1016/j.wasman.2011.03.024.

[31] O. Martínez-Alvarez, S. Chamorro, A. Brenes, Protein hydrolysates from animal processing by-products as a source of bioactive molecules with interest in animal feeding: A review, Food Res. Int. 73 (2015) 204-212. doi:10.1016/j.foodres.2015.04.005.

[32] W. Łaba, W. Kopeć, D. Chorążyk, A. Kancelista, M. Piegza, K. Malik, Biodegradation of pretreated pig bristles by Bacillus cereus B5esz, Int. Biodeterior. Biodegradation. 100 (2015) 116-123. doi:10.1016/j.ibiod.2015.02.024.

[33] M.C. Papadopoulos, A.R. El-Boushy, A.E. Roodbeen, The effect of varying autoclaving conditions and added sodium hydroxide on amino acid content and nitrogen characteristics of feather meal, J. Sci. Food Agric. 36 (1985) 1219-1226. doi:10.1002/jsfa.2740361204.

[34] M.T. Munir, S.S. Mansouri, I.A. Udugama, S. Baroutian, K. V. Gernaey, B.R. Young, 
Resource recovery from organic solid waste using hydrothermal processing: Opportunities and challenges, Renew. Sustain. Energy Rev. 96 (2018) 64-75.

doi:10.1016/j.rser.2018.07.039.

[35] W.E. McCasland, L.R. Richardson, Methods for Determining the Nutritive Value of Feather Meals, Poult. Sci. 45 (1966) 1231-1236. doi:10.3382/ps.0451231.

[36] J.D. Latshaw, N. Musharaf, R. Retrum, Processing of feather meal to maximize its nutritional value for poultry, Anim. Feed Sci. Technol. 47 (1994) 179-188. doi:10.1016/03778401(94)90122-8.

[37] K. Chojnacka, H. Górecka, I. Michalak, H. Górecki, A Review: Valorization of Keratinous Materials, Waste and Biomass Valorization. 2 (2011) 317-321. doi:10.1007/s12649-0119074-6.

[38] A. Bertsch, N. Coello, A biotechnological process for treatment and recycling poultry feathers as a feed ingredient, Bioresour. Technol. 96 (2005) 1703-1708. doi:10.1016/j.biortech.2004.12.026.

[39] A.M. Mazotto, J.L.R. Ascheri, R.L. de Oliveira Godoy, M.C. Triches Damaso, S. Couri, A.B. Vermelho, Production of feather protein hydrolyzed by B. subtilis AMR and its application in a blend with cornmeal by extrusion, LWT. 84 (2017) 701-709. doi:10.1016/j.lwt.2017.05.077.

[40] F.C. Falco, Microbial degradation of keratin-rich porcine by-products for protein hydrolysate production: a process engineering perspective, Technical University of Denmark (DTU), 2019.

[41] T.A. Brzustowski, Flaring in the energy industry, Prog. Energy Combust. Sci. 2 (1976) 129141. doi:10.1016/0360-1285(76)90009-5.

[42] C. Elvidge, T. Ghosh, F.-C. Hsu, K. Baugh, M. Zhizhin, Methods for Global Survey of Natural Gas Flaring from Visible Infrared Imaging Radiometer Suite Data, Energies. 9 (2015) 14. doi:10.3390/en9010014.

[43] NOAA, Global Gas Flaring Observed from Space, (n.d.).

[44] United Nations, Reduce Global Gas Flaring, (2019).

[45] J. Villadsen, J. Nielsen, G. Lidén, Bioreaction Engineering Principles, 3rd ed., Springer US, 2011.

[46] L.A.H. Petersen, J. Villadsen, S.B. Jørgensen, K. V. Gernaey, Mixing and mass transfer in a pilot scale U-loop bioreactor, Biotechnol. Bioeng. 114 (2017) 344-354.

doi:10.1002/bit.26084.

[47] C. Lieven, L.A.H. Petersen, S.B. Jørgensen, K. V. Gernaey, M.J. Herrgard, N. Sonnenschein, A Genome-Scale Metabolic Model for Methylococcus capsulatus (Bath) Suggests Reduced Efficiency Electron Transfer to the Particulate Methane Monooxygenase, Front. Microbiol. 9 (2018) 1-15. doi:10.3389/fmicb.2018.02947.

[48] Unibio, Unibio website, (n.d.).

[49] Calysta, Calysta website, (n.d.).

[50] P. Dürre, Fermentative Butanol Production, Ann. N. Y. Acad. Sci. (2008). doi:10.1196/annals.1419.009.

[51] B.G. Harvey, H.A. Meylemans, The role of butanol in the development of sustainable fuel technologies, J. Chem. Technol. Biotechnol. (2011). doi:10.1002/jctb.2540.

[52] S.Y. Lee, J.H. Park, S.H. Jang, L.K. Nielsen, J. Kim, K.S. Jung, Fermentative butanol 
production by clostridia, Biotechnol. Bioeng. (2008). doi:10.1002/bit.22003.

[53] R.C. Kuhn, L.J. Visioli, H. Enzweiler, M. Schwaab, M.A. Mazutti, Recent advances on biobutanol production, Sustain. Chem. Process. (2014). doi:10.1186/2043-7129-2-15.

[54] S. Chu, Y. Cui, N. Liu, The path towards sustainable energy, Nat. Mater. (2016). doi:10.1038/nmat4834.

[55] D.T. Jones, D.R. Woods, Acetone-butanol fermentation revisited., Microbiol. Rev. (1986).

[56] T. Lütke-Eversloh, H. Bahl, Metabolic engineering of Clostridium acetobutylicum: Recent advances to improve butanol production, Curr. Opin. Biotechnol. (2011). doi:10.1016/j.copbio.2011.01.011.

[57] Y. Kharayat, Distillery wastewater: bioremediation approaches, J. Integr. Environ. Sci. (2012). doi:10.1080/1943815X.2012.688056.

[58] H. Bahl, W. Andersch, K. Braun, G. Gottschalk, Effect of pH and butyrate concentration on the production of acetone and butanol by Clostridium acetobutylicum grown in continuous culture, Eur. J. Appl. Microbiol. Biotechnol. (1982). doi:10.1007/BF00507998.

[59] F. Xin, W. Yan, J. Zhou, H. Wu, W. Dong, J. Ma, W. Zhang, M. Jiang, Exploitation of novel wild type solventogenic strains for butanol production, Biotechnol. Biofuels. (2018). doi:10.1186/s 13068-018-1252-3.

[60] J. Zheng, Y. Tashiro, Q. Wang, K. Sonomoto, Recent advances to improve fermentative butanol production: Genetic engineering and fermentation technology, J. Biosci. Bioeng. (2015). doi:10.1016/j.jbiosc.2014.05.023.

[61] J. Rodríguez, R. Kleerebezem, J.M. Lema, M.C.M. Van Loosdrecht, Modeling product formation in anaerobic mixed culture fermentations, Biotechnol. Bioeng. (2006). doi:10.1002/bit.20765.

[62] R. Kleerebezem, M.C. van Loosdrecht, Mixed culture biotechnology for bioenergy production, Curr. Opin. Biotechnol. (2007). doi:10.1016/j.copbio.2007.05.001.

[63] L.T. Angenent, H. Richter, W. Buckel, C.M. Spirito, K.J.J. Steinbusch, C.M. Plugge, D.P.B.T.B. Strik, T.I.M. Grootscholten, C.J.N. Buisman, H.V.M. Hamelers, Chain Elongation with Reactor Microbiomes: Open-Culture Biotechnology to Produce Biochemicals, Environ. Sci. Technol. (2016). doi:10.1021/acs.est.5b04847.

[64] K. Johnson, Y. Jiang, R. Kleerebezem, G. Muyzer, M.C.M. Van Loosdrecht, Enrichment of a mixed bacterial culture with a high polyhydroxyalkanoate storage capacity, in: Biomacromolecules, 2009. doi:10.1021/bm8013796.

[65] K.J.J. Steinbusch, H.V.M. Hamelers, C.M. Plugge, C.J.N. Buisman, Biological formation of caproate and caprylate from acetate: Fuel and chemical production from low grade biomass, Energy Environ. Sci. (2011). doi:10.1039/c0ee00282h.

[66] T.I.M. Grootscholten, K.J.J. Steinbusch, H.V.M. Hamelers, C.J.N. Buisman, Improving medium chain fatty acid productivity using chain elongation by reducing the hydraulic retention time in an upflow anaerobic filter, Bioresour. Technol. (2013). doi:10.1016/j.biortech.2013.02.114.

[67] P.R. Mooij, G.R. Stouten, M.C.M. van Loosdrecht, R. Kleerebezem, Ecology-based selective environments as solution to contamination in microalgal cultivation, Curr. Opin. Biotechnol. (2015). doi:10.1016/j.copbio.2014.11.001.

[68] P.L. McCarty, D.P. Smith, Anaerobic wastewater treatment, Environ. Sci. Technol. (1986). doi:10.1021/es00154a002. 
[69] B. Schink, Energetics of syntrophic cooperation in methanogenic degradation., Microbiol. Mol. Biol. Rev. (1997). doi:1092-2172/97/\$04.0010.

[70] P. Merlin Christy, L.R. Gopinath, D. Divya, A review on anaerobic decomposition and enhancement of biogas production through enzymes and microorganisms, Renew. Sustain. Energy Rev. (2014). doi:10.1016/j.rser.2014.03.010.

[71] P.G. Kougias, I. Angelidaki, Biogas and its opportunities-A review, Front. Environ. Sci. Eng. (2018). doi:10.1007/s11783-018-1037-8.

[72] H.H.P. Fang, H.Q. Yu, Acidification of Lactose in Wastewater, J. Environ. Eng. (2002). doi:10.1061/(asce)0733-9372(2001)127:9(825).

[73] H.Q. Yu, Y. Mu, H.H.P. Fang, Thermodynamic analysis of product formation in mesophilic acidogenesis of lactose, Biotechnol. Bioeng. (2004). doi:10.1002/bit.20190.

[74] H. Junicke, M.C.M. van Loosdrecht, R. Kleerebezem, Kinetic and thermodynamic control of butyrate conversion in non-defined methanogenic communities, Appl. Microbiol. Biotechnol. (2016). doi:10.1007/s00253-015-6971-9.

[75] K.J.J. Steinbusch, H.V.M. Hamelers, C.J.N. Buisman, Alcohol production through volatile fatty acids reduction with hydrogen as electron donor by mixed cultures, Water Res. (2008). doi:10.1016/j.watres.2008.05.032.

[76] H. Richter, N. Qureshi, S. Heger, B. Dien, M.A. Cotta, L.T. Angenent, Prolonged conversion of n-butyrate to n-butanol with Clostridium saccharoperbutylacetonicum in a two-stage continuous culture with in-situ product removal, Biotechnol. Bioeng. (2012). doi:10.1002/bit.24380.

[77] M.T. Agler, B.A. Wrenn, S.H. Zinder, L.T. Angenent, Waste to bioproduct conversion with undefined mixed cultures: The carboxylate platform, Trends Biotechnol. (2011). doi:10.1016/j.tibtech.2010.11.006.

[78] R. Kleerebezem, B. Joosse, R. Rozendal, M.C.M. Van Loosdrecht, Anaerobic digestion without biogas?, Rev. Environ. Sci. Biotechnol. (2015). doi:10.1007/s11157-015-9374-6.

[79] C. Xue, G.Q. Du, L.J. Chen, J.G. Ren, F.W. Bai, Evaluation of asymmetric polydimethylsiloxane-polyvinylidene fluoride composite membrane and incorporated with acetone-butanol-ethanol fermentation for butanol recovery, J. Biotechnol. 188 (2014) 158165. doi:10.1016/j.jbiotec.2014.08.010.

[80] C.M. Mehta, W.O. Khunjar, V. Nguyen, S. Tait, D.J. Batstone, Technologies to Recover Nutrients from Waste Streams: A Critical Review, Crit. Rev. Environ. Sci. Technol. 45 (2015) 385-427. doi:10.1080/10643389.2013.866621.

[81] G. Tchobanoglous, F.L. Burton, H.D. Stensel, Metcalf \& Eddy Inc., Wastewater Engineering. Treatment and Reuse, 4th ed., McGraw Hill Higher Education, 2003.

[82] G.T. Daigger, Evolving Urban Water and Residuals Management Paradigms: Water Reclamation and Reuse, Decentralization, and Resource Recovery, Water Environ. Res. 81 (2009) 809-823. doi:10.2175/106143009X425898.

[83] U. Jeppsson, J. Alex, D.J. Batstone, L. Benedetti, J. Comas, J.B. Copp, L. Corominas, X. Flores-Alsina, K. V. Gernaey, I. Nopens, M.-N. Pons, I. Rodríguez-Roda, C. Rosen, J.-P. Steyer, P.A. Vanrolleghem, E.I.P. Volcke, D. Vrecko, Benchmark simulation models, quo vadis?, Water Sci. Technol. 68 (2013) 1-15. doi:10.2166/wst.2013.246.

[84] C. Kazadi Mbamba, X. Flores-Alsina, D. John Batstone, S. Tait, Validation of a plant-wide phosphorus modelling approach with minerals precipitation in a full-scale WWTP, Water Res. 100 (2016) 169-183. doi:10.1016/j.watres.2016.05.003. 
[85] M. Arnell, M. Rahmberg, F. Oliveira, U. Jeppsson, Multi-objective performance assessment of wastewater treatment plants combining plant-wide process models and life cycle assessment, J. Water Clim. Chang. 8 (2017) 715-729. doi:10.2166/wcc.2017.179.

[86] H. Hauduc, I. Takács, S. Smith, A. Szabo, S. Murthy, G.T. Daigger, M. Spérandio, A dynamic physicochemical model for chemical phosphorus removal, Water Res. 73 (2015) 157-170. doi:10.1016/j.watres.2014.12.053.

[87] K. Solon, X. Flores-Alsina, C. Kazadi Mbamba, D. Ikumi, E.I.P. Volcke, C. Vaneeckhaute, G. Ekama, P.A. Vanrolleghem, D.J. Batstone, K.V. Gernaey, U. Jeppsson, Plant-wide modelling of phosphorus transformations in wastewater treatment systems: Impacts of control and operational strategies, Water Res. 113 (2017) 97-110. doi:10.1016/j.watres.2017.02.007.

[88] L. Shu, P. Schneider, V. Jegatheesan, J. Johnson, An economic evaluation of phosphorus recovery as struvite from digester supernatant, Bioresour. Technol. 97 (2006) 2211-2216. doi:10.1016/j.biortech.2005.11.005.

[89] I.A. Udugama, M.A. Taube, S.S. Mansouri, R. Kirkpatrick, K. V. Gernaey, W. Yu, B.R. Young, A Systematic Methodology for Comprehensive Economic Assessment of Process Control Structures, Ind. Eng. Chem. Res. 57 (2018) 13116-13130. doi:10.1021/acs.iecr.8b01883.

[90] L. Egle, H. Rechberger, J. Krampe, M. Zessner, Phosphorus recovery from municipal wastewater: An integrated comparative technological, environmental and economic assessment of P recovery technologies, Sci. Total Environ. 571 (2016) 522-542. doi:10.1016/j.scitotenv.2016.07.019.

[91] M.P. Lapinski, S. Metro, P.R. Pujadó, M. Moser, Catalytic Reforming in Petroleum Processing, in: Handb. Pet. Process., Springer International Publishing, Cham, 2015: pp. 229-260. doi:10.1007/978-3-319-14529-7_1.

[92] S.S. Mansouri, C.L. Gargalo, I.A. Udugama, P. Ramin, M. Sales-Cruz, G. Sin, K. V. Gernaey, Economic Risk Analysis and Critical Comparison of Biodiesel Production Systems, in: 2019: pp. 127-148. doi:10.1007/978-3-030-00985-4_6.

[93] S.S. Mansouri, I.A. Udugama, A. Mitic, K. V. Gernaey, Reverse osmosis for water purification and reuse in the biotechnological industry: Process design, operation and economic guidelines, Comput. Aided Chem. Eng. 40 (2017).

[94] Biopro, BIOPRO strengthens Danish biotech, (2017). http://www.biopro.nu/default.asp?Action=Details\&Item=76.

[95] I. A. Udugama, H. Feldman, S.C. de las Heras, A. Kizhedath, J. Bryde-Jacobsen, F. van den Berg, S.S. Mansouri, K. V. Gernaey, BIOPRO World Talent Campus: A week of real world challenge for biotechnology post-graduate students, Educ. Chem. Eng. 25 (2018) 1-8. doi:10.1016/j.ece.2018.08.005.

[96] B. Li, I.A. Udugama, S.S. Mansouri, W. Yu, S. Baroutian, K. V. Gernaey, B.R. Young, An exploration of barriers for commercializing phosphorus recovery technologies, J. Clean. Prod. 229 (2019) 1342-1354. doi:10.1016/j.jclepro.2019.05.042.

[97] M.A. Kraller, I.A. Udugama, R. Kirkpatrick, W. Yu, B.R. Young, Side draw optimisation of a high-purity, multi-component distillation column, Asia-Pacific J. Chem. Eng. 11 (2016) 958-972. doi:10.1002/apj.2030.

[98] I.A. Udugama, F. Wolfenstetter, R. Kirkpatrick, W. Yu, B.R. Young, A comparison of a novel robust decentralised control strategy and MPC for industrial high purity, high recovery, multicomponent distillation, ISA Trans. 69 (2017) 222-233. 
doi:10.1016/j.isatra.2017.04.008.

[99] I. A. Udugama, M.T. Munir, R. Kirkpatrick, B.R. Young, W. Yu, Side draw control design for a high purity multi-component distillation column, ISA Trans. 76 (2018) 167-177. doi:10.1016/j.isatra.2018.03.006. 
A)

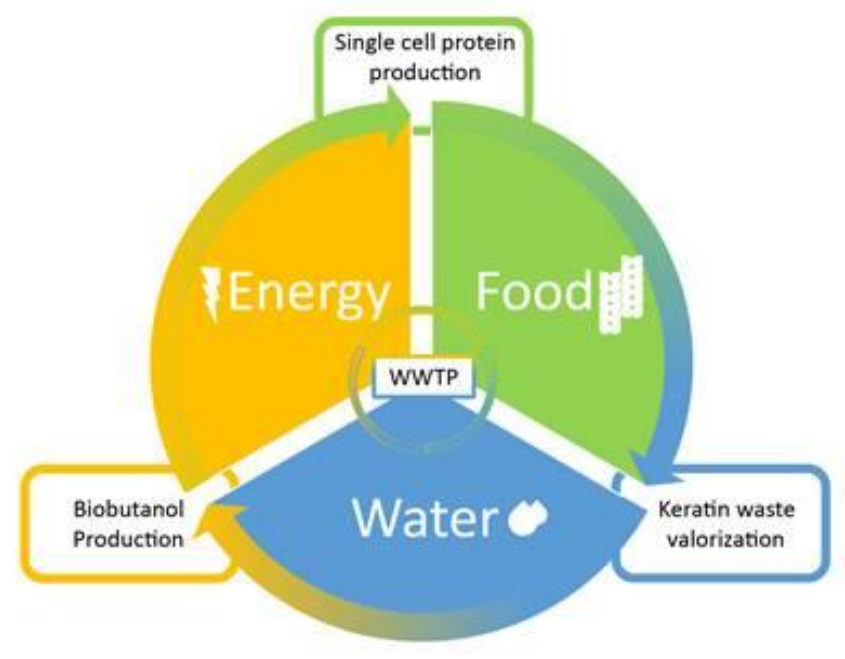

B)

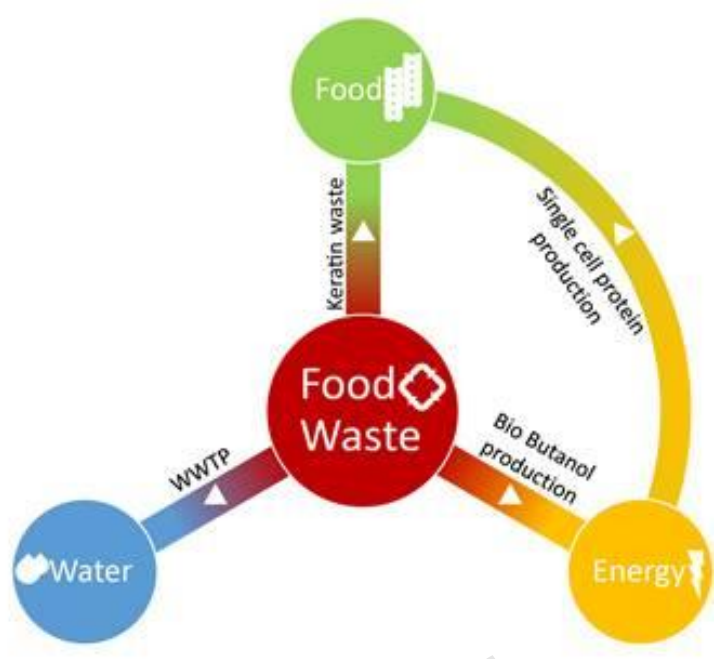

Figure 1. Graphical illustration of which pillar of the WEF nexus each of the four case studies addresses. In A) this is illustrated in a traditional manner, where food waste specifically is used as origin in B).

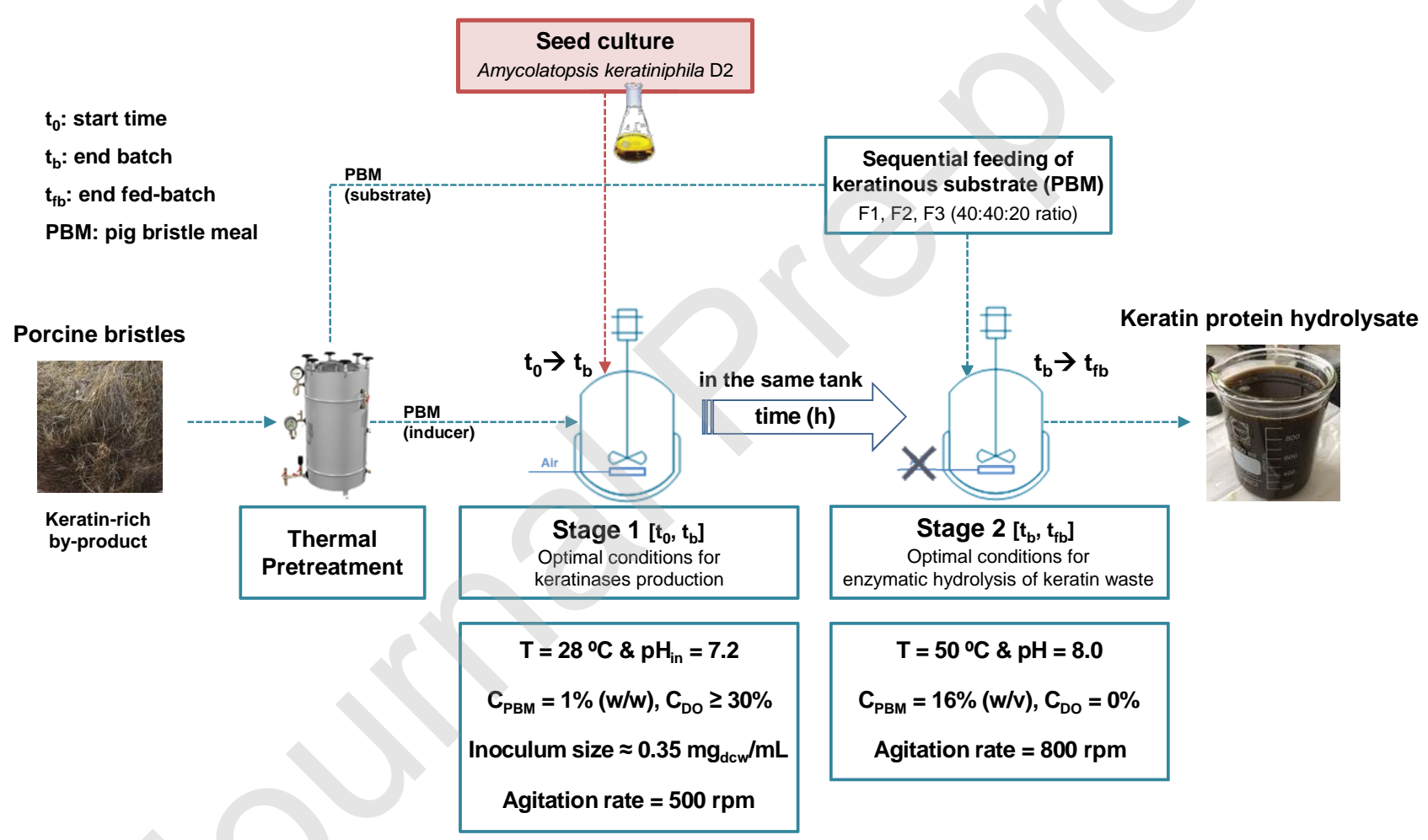

Figure 2. Two-stage microbial degradation process in which both production of keratinolytic enzymes and hydrolysis of keratinous waste takes place. 


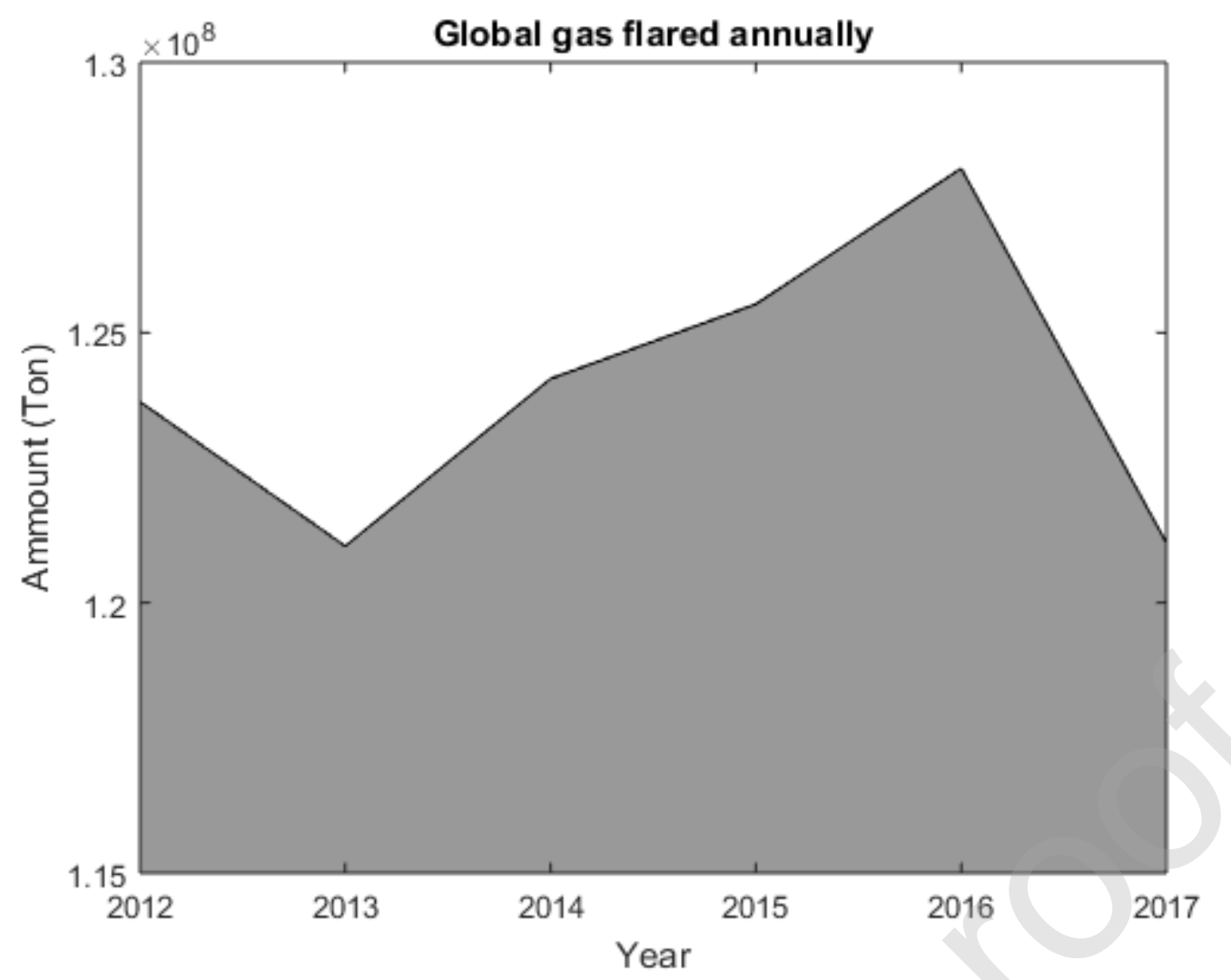

Figure 3. Tons of gas flared on a global scale from year 2012 to 2017. Data is estimated according to satellite imaging $[42,43]$ 


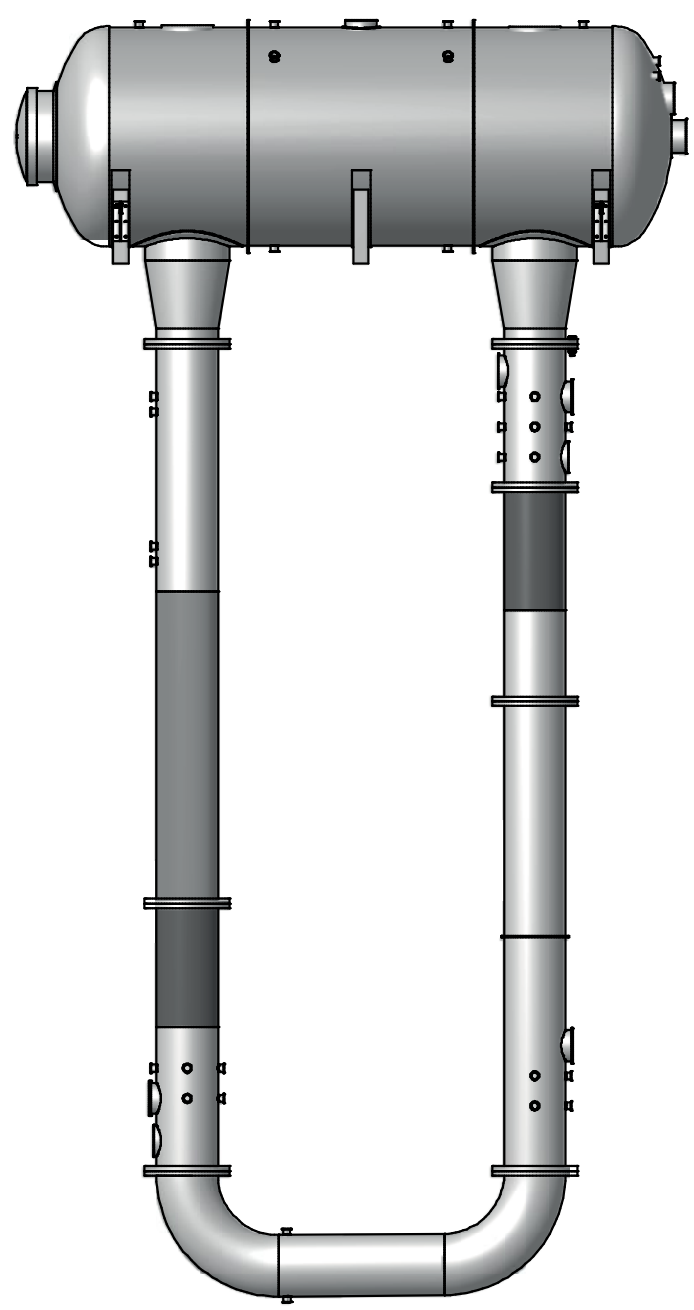

Figure 4. Picture of the loop bioreactor (U-loop fermentor) used by Unibio in their production of single cell protein. Calysta employs a similar design. 
a

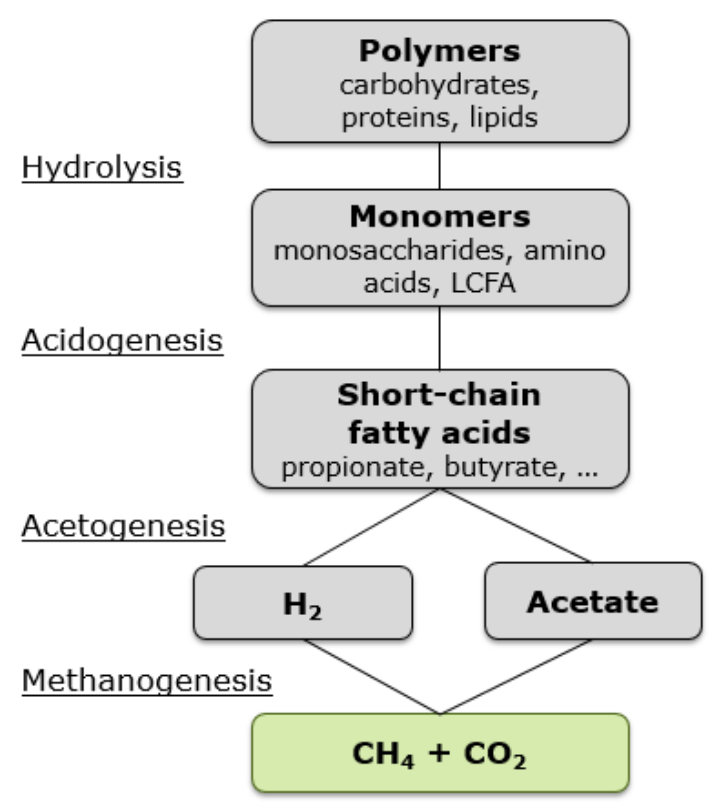

b

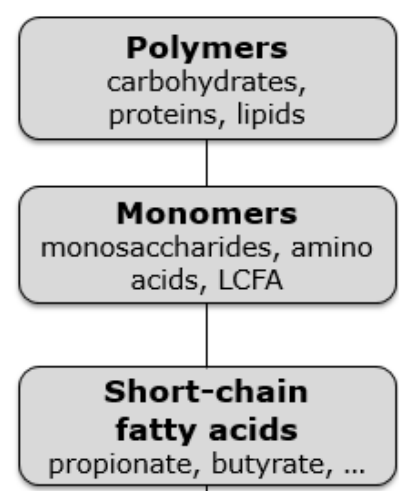

Solventogenesis

\section{C2-C5 alcohols}

Figure 5. Schematic overview of the anaerobic digestion process with biogas as the final product (a) and the proposed alternative pathway for alcohol production at low $\mathrm{pH}$ and increased hydrogen partial pressure. Under such conditions, the final two steps of the anaerobic digestion process, namely acetogenesis and methanogenesis, are inhibited, while solventogensis is favored.

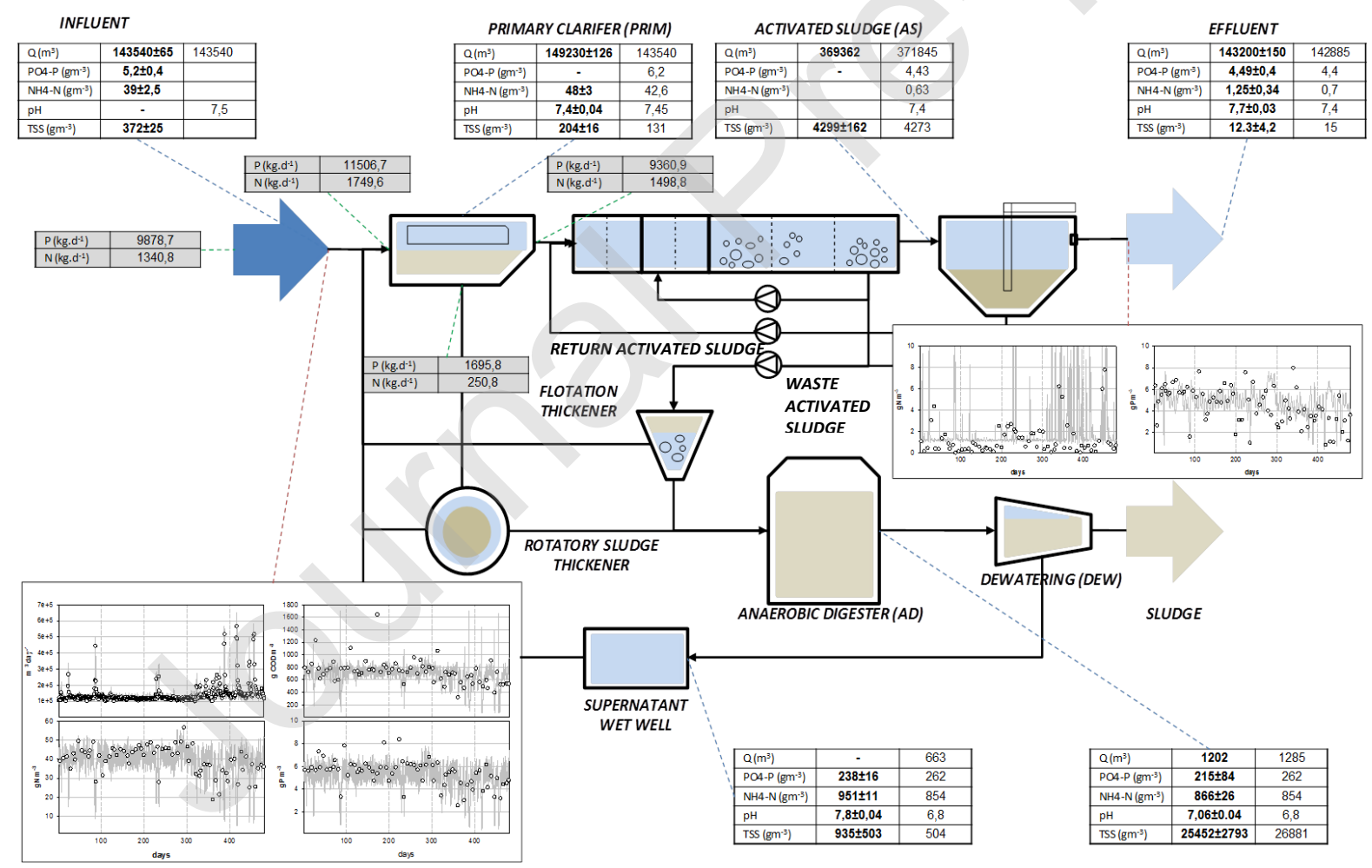

Figure 6. A schematic of the calibrated wastewater treatment plant model with mass balance information 


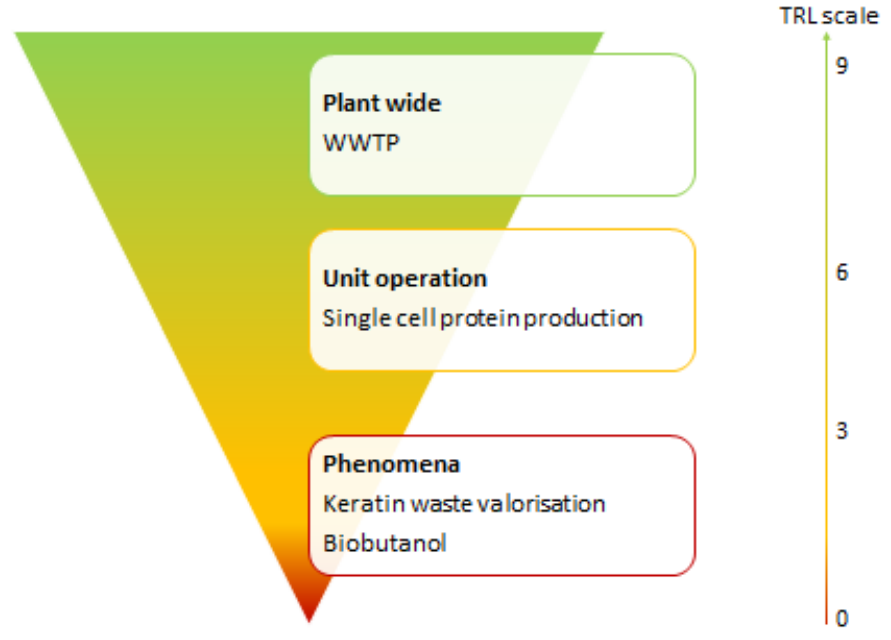

Figure 7. The scientific focus of the case studies in terms of process aggregation (development) and their respective overall TRL. 